\title{
Prevalence of lysosomal storage diseases in Portugal
}

\author{
Rui Pinto ${ }^{1,2}$, Carla Caseiro ${ }^{1}$, Manuela Lemos ${ }^{1}$, Lurdes Lopes ${ }^{1}$, Augusta Fontes ${ }^{1}$, \\ Helena Ribeiro ${ }^{1}$, Eugénia Pinto ${ }^{1}$, Elisabete Silva ${ }^{1}$, Sónia Rocha ${ }^{1}$, Ana Marcão ${ }^{2}$, \\ Isaura Ribeiro $^{1,2}$, Lúcia Lacerda ${ }^{1,2}$, Gil Ribeiro ${ }^{1,2}$, Olga Amaral ${ }^{1,2}$, MC Sá Miranda*,1,2 \\ ${ }^{1}$ Instituto de Genética Médica Jacinto de Magalhães, Porto, Portugal; ${ }^{2}$ Instituto de Biologia Molecular \& Celular \\ (IBMC), Portugal
}

Lysosomal storage diseases (LSDs) are a group of inherited metabolic disorders individually considered as rare, and few data on its prevalence has been reported in the literature. The overall birth prevalence of the 29 different LSDs studied in the Portuguese population was calculated to be 25/100 000 live births, twice the prevalence previously described in Australia and in The Netherlands. The comparison of the prevalence profile of the LSDs presenting a prevalence higher than $0.5 / 100000$ in the Portuguese, Dutch and Australian populations showed, in the Portuguese, the existence of a higher prevalence of GM2 gangliosidoses (B variant), mucolipidoses (II and III), Niemman-Pick type C and metachromatic leukodystrophy (MLD), and a lower prevalence of Pompe and Fabry. The highest prevalence value for a single LSD is the one of GM2 gangliosidoses (B variant), corresponding to 3/100000, a value which is significantly higher than the prevalence of the most frequent LSD in Dutch, Pompe disease $(2 / 100000)$ and Australians, Gaucher's disease (GD) (1.8/100000). It is worth noting that the highest prevalence of GM2 gangliosidoses found in the Portuguese is mainly due to the existence of a unique subtype, the rare juvenile B1 variant.

European Journal of Human Genetics (2004) 12, 87-92. doi:10.1038/sj.ejhg.5201044

Published online 17 December 2003

Keywords: inherited metabolic disorders; lysosomal storage diseases; genetic epidemiology; birth prevalence; Portuguese population

\section{Introduction}

Lysosomal storage disorders (LSDs) are a heterogeneous group of inherited metabolic diseases characterized by the impairment of the intralysosomal catabolic pathways (for a recent review, see the corresponding chapters in Scriver et $a l^{1}$ ).

With the exception of particular diseases in specific ethnic groups, few data on the frequency of LSDs can be found in the literature ${ }^{1}$ and, as far as we know, prevalence data on LSDs considered as a group have only been reported in The Netherlands ${ }^{2}$ and in Australia. ${ }^{3}$ Besides contributing to the knowledge of the genetic character-

*Correspondence: Dr MC Sá Miranda, IBMC, Rua do Campo Alegre 823, 4150-180 Porto, Portugal. Tel.: 35122607 4970; Fax: 351226092404 E-mail: mcsamir@ibmc.up.pt

Received 16 August 2002; revised 28 April 2003; accepted 13 May 2003 istics of each population, prevalence data are important to delineate prevention and therapeutic strategies.

Between 1982 and 2001, 353 patients with an LSD were identified in this laboratory by studying 29 different LSDs in about 4700 cases suspected of an Inherited metabolic disease. On the basis of these data, we report for the first time, the relative frequency and the birth prevalence of LSDs in a Southern European population.

\section{Patients and methods}

Geographical origin of the cases studied

The Enzymology Unit of Instituto de Genética Médica Jacinto de Magalhães, located in Porto, is the only Portuguese Laboratory providing post- and prenatal diagnosis of LSDs and receiving samples from Health Services located throughout the country. Probably due to its geographical location, in the North of Portugal, a higher 
number of requests are received from Health Services located in the North and Central regions of the country than from other regions. Since there is only one other Portuguese laboratory, located in Lisbon, offering postnatal diagnosis for just a few LSDs, during the last 10 years a time tendency for a more uniform coverage of the country by our lab has been observed (data not shown). The relative frequency was determined considering two groups of patients, according to their possible origin, from the North and from other regions. As the population from the Northern part of the country has been studied more extensively, we decided to use only these data in the birth prevalence calculation.

\section{Analytical methods}

Current methodology, extensively reviewed, was used in the determination of enzyme activities ${ }^{4,5}$ and in the analysis of substrates. ${ }^{6,7}$ Standard molecular biology techniques, such as PCR, SSCP, RFLP and sequencing, were used in mutation analysis. Genotype analysis was performed to exclude pseudodeficiency alleles in $\mathrm{MLD}^{8}$ to identify polymorphisms responsible for low enzymatic activity in Krabbe's disease ${ }^{9}$ and as diagnostic criteria in NCL $3 .^{10}$ Genotype analysis was also carried out in the four most frequent sphingolipidoses. ${ }^{11}$

\section{Patients}

In general, the enzymatic activity was determined in a blood sample, and subsequently confirmed in cultured skin fibroblasts. Urinary excretion of substrates was considered in mucopolysaccharidoses (MPSs), oligosaccharidoses and metachromatic leukodystrophy. Patient's birthplace, age and clinical phenotype were collected from the laboratory records.

\section{Prevalence estimation}

Prevalence was calculated for each disease by dividing the total number of diagnosed cases (post- and prenatal diagnosis) by the total number of live births that occurred between the years of birth of the older and the younger patients (birth period). In relation to GM2 gangliosidosis B variant and MLD, diseases presenting three different clinical phenotypes (infantile, juvenile and adult or chronic), the prevalence of each phenotype was determined and the overall prevalence was calculated by adding the prevalence of each phenotype. The noneuronopathic form of GD (type 1) includes a very wide spectrum of clinical phenotypes, the age of onset ranging between 3 and 80 years. In order to overcome the underestimation due to the very large birth period, two subgroups were considered according to the age of clinical manifestations, before and after 15 years age. For diseases in which only one patient was diagnosed, the prevalence was calculated using the number of live births during the ascertainment period (1982-2001). Data on the number of live births in
Portugal were collected at the Instituto Nacional de Estatistica, Porto, Portugal.

\section{Results}

The relative frequency of LSDs in Portuguese population from the North and from other regions is compared in Table 1. Three main groups were considered:

MPSs (MLP), sphingolipidoses and oligosaccharidoses; mucolipidoses, Pompe and neuronal ceroid lipofuscinoses were considered apart. The relative frequency of each LSD was calculated: in relation to the total number of diagnosed patients and in relation to the number of patients of each main group considered. As a group, MPSs and sphingolipidoses present similar frequencies in populations of both geographical regions. Exceptions to the relatively uniform distribution of MPSs along the country are MPS I and II. The first one (Hurler's disease) represents $13 \%$ in the North and $35 \%$ in the rest of the country; in contrast, Hunter's disease represents 34 and $8 \%$ of the MPS in the same respective regions. The relatively high frequency of MPS III (Sanfilippo) among MPSs is mainly due to MPS IIIB.

Regarding the sphingolipidoses, the most striking difference between both samples is the higher frequency of MLD in the North (17 vs 2\%). Mucolipidoses (II and III), generally considered as rare, account for 11 patients out of 353. Neuronal ceroid lipofuscinoses (NCL), whose study begun only in 1999, account for $7 \%$ of total LSDs in the Northern and 5\% in the non-Northern samples.

Birth prevalence was calculated using the more extensively studied Northern Portuguese population data. Table 2 compares the results obtained with the birth prevalence previously described in the Netherlands ${ }^{2}$ and in Australia. ${ }^{3}$

Genotype analysis data were used to investigate if the high prevalence of the more frequent sphingolipidoses was due to a high frequency of particular mutations. As can be observed in Table 3, one single mutation represents 58, 53 and $64 \%$ of the mutated alleles in unrelated patients with Tay-Sachs disease, Gaucher's disease and MLD, respectively.

\section{Discussion}

Overall, the birth prevalence of LSD determined in the Northern Portuguese population (25 per 100000 live births) is about the double of that previously reported in the Netherlands ${ }^{2}$ and in Australia; ${ }^{3}$ it must be noticed that the observed discrepancies cannot be explained by the slight differences in the calculation methods. In fact, the incidence rates of the different LSDs in the Portuguese (data not shown) are similar to the birth prevalence values presented. When only MPSs are considered, birth prevalence (4.8 per 100000) is very close to the values previously reported. ${ }^{2,3}$ In contrast, the sphingolipidoses 
Table 1 Relative frequency of LSD in Portugal

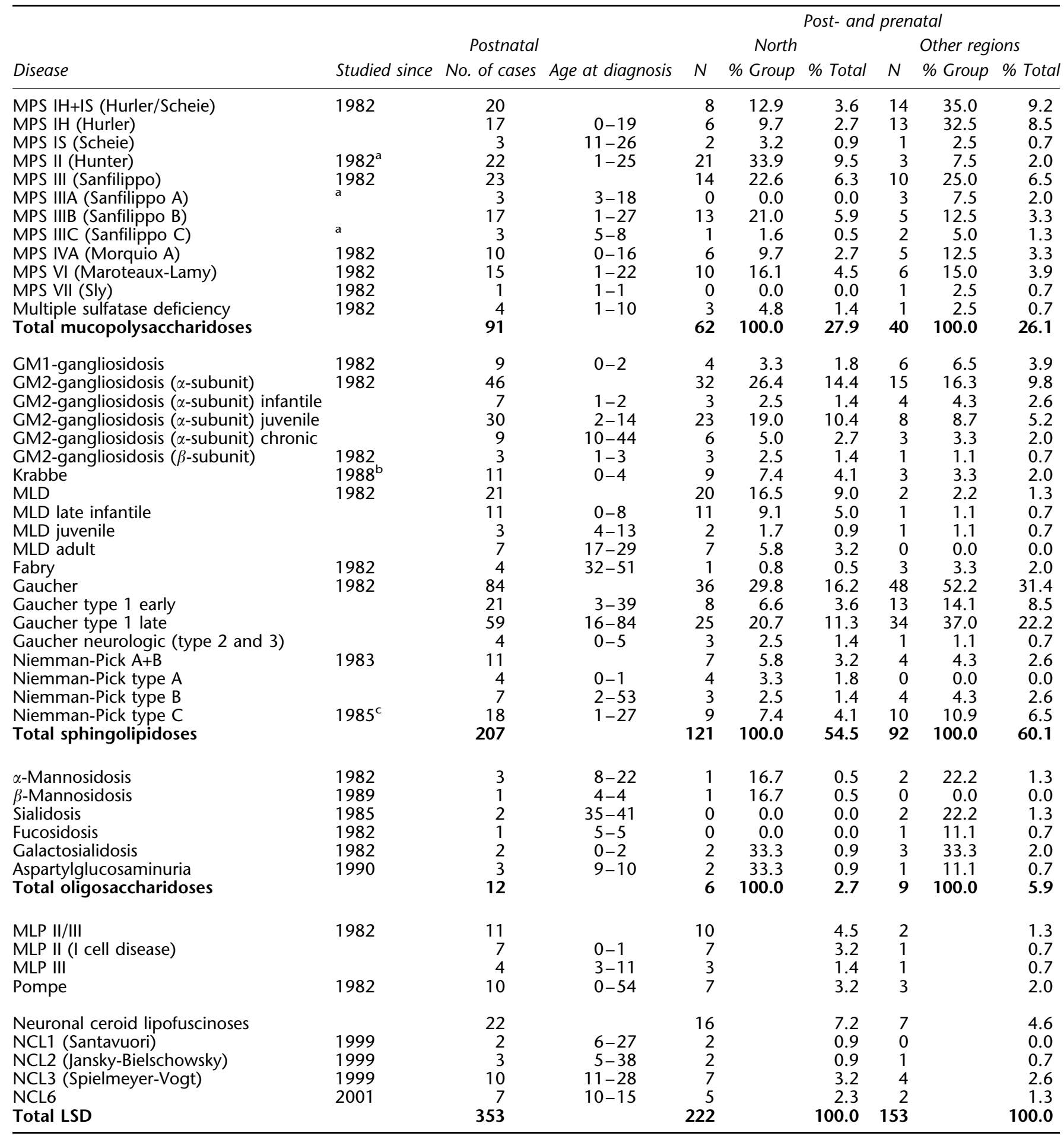

Some diagnoses have been confirmed by

${ }^{\mathrm{a} O}$. van Diggelen and WJ Kleijer (Rotterdam).

${ }^{b}$ MT Vanier (Lyon) and D Wenger (Philadelphia).

${ }^{\mathrm{c}} \mathrm{MT}$ Vanier (Lyon). MPS = Mucopolysaccharidoses; $\mathrm{p} / \mathrm{MLP}=$ Mucolipidoses; $\mathrm{NCL}=$ Neuronal Ceroid Lipofuscinoses. 
Table 2 Birth Prevalence of LSD

\begin{tabular}{|c|c|c|c|c|c|}
\hline \multirow[b]{3}{*}{ Disease } & \multicolumn{5}{|c|}{ Post and prenatal } \\
\hline & \multicolumn{2}{|c|}{ Northern Portugal } & \multicolumn{3}{|c|}{ Birth prevalence* } \\
\hline & No. of cases & Birth period & $N P$ & $N L(2)$ & $A U(3)$ \\
\hline MPS IH+IS (Hurler/Scheie) & 8 & & 1.33 & 1.19 & 1.14 \\
\hline MPS IH (Hurler) & 6 & 1984-1995 & 1.05 & & \\
\hline MPS IS (Scheie) & 2 & 1976-1987 & 0.28 & & \\
\hline MPS II (Hunter) & 21 & $1967-2000$ & 1.09 & 0.67 & 0.74 \\
\hline MPS III (Sanfilippo) & 14 & & 0.84 & $1.89^{\mathrm{a}}$ & \\
\hline MPS IIIA (Sanfilippo A) & 0 & & 0.00 & 1.16 & 0.88 \\
\hline MPS IIIB (Sanfilippo B) & 13 & 1966-1994 & 0.72 & 0.42 & 0.47 \\
\hline MPS IIIC (Sanfilippo C) & 1 & $1982-2001$ & 0.12 & 0.21 & 0.07 \\
\hline MPS IVA (Morquio A) & 6 & 1979-1998 & 0.60 & 0.22 & 0.59 \\
\hline MPS VI (Maroteaux-Lamy) & 10 & $1962-1999$ & 0.42 & 0.15 & 0.43 \\
\hline MPS VII (Sly) & 0 & & 0.00 & 0.24 & 0.05 \\
\hline Multiple sulfatase deficiency & 3 & 1978-1988 & 0.48 & 0.05 & 0.07 \\
\hline Total mucopolysaccharidoses & 62 & & 4.8 & $4.5^{\mathrm{b}}$ & \\
\hline GM1-gangliosidosis & 4 & 1985-1998 & 0.62 & 0.41 & 0.26 \\
\hline GM2-gangliosidosis ( $\alpha$-subunit) & 32 & & 3.13 & 0.41 & 0.50 \\
\hline GM2-gangliosidosis ( $\alpha$-subunit) infantile & 3 & $1985-1990$ & 1.02 & & \\
\hline GM2-gangliosidosis ( $\alpha$-subunit) juvenile & 23 & 1974-1997 & 1.77 & & \\
\hline GM2-gangliosidosis ( $\alpha$-subunit) chronic & 6 & $1959-1980$ & 0.34 & & \\
\hline GM2-gangliosidosis ( $\beta$-subunit) & 3 & $1985-1988$ & 1.49 & 0.34 & 0.26 \\
\hline Krabbe & 9 & 1984-1999 & 1.21 & 1.35 & 0.71 \\
\hline MLD & 20 & & 1.85 & $1.42^{\mathrm{C}}$ & 1.09 \\
\hline MLD late infantile & 11 & $1980-2001$ & 1.12 & 0.52 & \\
\hline MLD juvenile & 2 & 1974-1984 & 0.29 & 0.51 & \\
\hline MLD adult & $\overline{7}$ & $1954-1971$ & 0.45 & 0.24 & \\
\hline Fabry & 1 & $1982-2001$ & 0.12 & 0.21 & 0.86 \\
\hline Gaucher & 36 & & 1.35 & 1.16 & 1.75 \\
\hline Gaucher type 1 early & 8 & 1953-1987 & 0.30 & 0.26 & \\
\hline Gaucher type 1 late & 25 & $1917-1981$ & 0.50 & 0.64 & \\
\hline Gaucher neurologic (type 2 and 3 ) & 3 & $1977-1985$ & 0.55 & 0.26 & \\
\hline Niemman-Pick A+B & 7 & & 0.60 & 0.53 & 0.40 \\
\hline Niemman-Pick type A & 4 & $1983-2000$ & 0.50 & & \\
\hline Niemman-Pick type B & 3 & 1952-1991 & 0.10 & & \\
\hline Niemman-Pick type C & 9 & 1979-1985 & 2.20 & 0.35 & 0.47 \\
\hline Total sphingolipidoses & 121 & & 12.6 & 6.2 & \\
\hline$\alpha$-Mannosidosis & 1 & 1982-2001 & 0.12 & 0.09 & 0.10 \\
\hline$\beta$-Mannosidosis & 1 & $1982-2001$ & 0.12 & 0.13 & \\
\hline Sialidosis & 0 & & 0.00 & 0.05 & 0.02 \\
\hline Fucosidosis & 0 & & 0.00 & 0.05 & \\
\hline Galactosialidosis & 2 & $1994-2001$ & 0.77 & 0.04 & \\
\hline Aspartylglucosaminuria & 2 & $1982-1983$ & 1.72 & 0.13 & 0.05 \\
\hline Total oligosaccharidoses & 6 & & 2.7 & & \\
\hline MLP II/III & 10 & & 2.70 & & 0.31 \\
\hline MLP II (I cell disease) & 7 & $1982-2000$ & 0.81 & 0.16 & \\
\hline MLP III & 3 & $1984-1986$ & 1.89 & 0.08 & \\
\hline Pompe & 7 & $1940-1999$ & 0.17 & 2.0 & 0.69 \\
\hline Neuronal ceroid lipofuscinoses & 16 & & 2.14 & & \\
\hline NCL1 (Santavuori) & 2 & $1974-1994$ & 0.17 & & \\
\hline NCL2 (Jansky-Bielschowsky) & 2 & $1950-1987$ & 0.07 & & \\
\hline NCL3 (Spielmeyer-Vogt) & 7 & 1973-1999 & 0.48 & & \\
\hline NCL6 & 5 & $1984-1990$ & 1.43 & & \\
\hline Total LSD & 222 & & 25 & $14^{\mathrm{d}}$ & 12.99 \\
\hline
\end{tabular}

ancludes MPS IIID.

Includes MPS IIID and MPS IVB.

'Includes some unspecified types.

'Includes Schindler, and ISSD does not include NCL.

$\mathrm{NP}=$ Northern Portugal; $\mathrm{NL}=$ Netherlands; $\mathrm{AU}=$ Australia. *Birth prevalence expressed as number of cases per 100000 live births. 
Table 3 Frequency of mutated alleles in unrelated Portuguese patients with the four most frequent sphingolipidoses: MLD, GM2-Gangliosidosis, Gaucher and Niemann-Pick type $C$ diseases

\begin{tabular}{|c|c|c|c|c|}
\hline Gene & Mutation & MIM Id & Nb alleles & $\%$ \\
\hline Total & $\begin{array}{l}\text { ivs } 2+1 \\
\text { I179S } \\
\text { Other }\end{array}$ & $\begin{array}{l}250100.0033 \\
250100.0008\end{array}$ & $\begin{array}{r}18 \\
2 \\
10 \\
30\end{array}$ & $\begin{array}{r}60.0 \\
6.7 \\
33.3 \\
100.0\end{array}$ \\
\hline HEXA & $\begin{array}{l}\text { R178H } \\
\text { R137X } \\
\text { Other }\end{array}$ & $\begin{array}{l}606869.0006 \\
606869.0019\end{array}$ & $\begin{array}{r}44 \\
7 \\
23 \\
74\end{array}$ & $\begin{array}{r}59.5 \\
9.5 \\
31.1 \\
100.0\end{array}$ \\
\hline GBA & $\begin{array}{l}\text { N370S } \\
\text { L444P } \\
\text { Other }\end{array}$ & $\begin{array}{l}606463.0003 \\
606463.0001\end{array}$ & $\begin{array}{r}68 \\
18 \\
42 \\
128\end{array}$ & $\begin{array}{r}53.1 \\
14.1 \\
32.8 \\
100.0\end{array}$ \\
\hline NPC1 & $\begin{array}{c}\text { A1035V } \\
\text { C177Y } \\
\text { I1061T } \\
\text { Other }\end{array}$ & $\begin{array}{l}257220.0017 \\
257220.0016 \\
257220.0010\end{array}$ & $\begin{array}{r}5 \\
3 \\
2 \\
24 \\
34\end{array}$ & $\begin{array}{r}14.7 \\
8.8 \\
5.9 \\
70.6 \\
100.0\end{array}$ \\
\hline
\end{tabular}

birth prevalence (12.6 per 100000 live births) in the Northern Portuguese population is the double of the birth prevalence reported in the Dutch (6.2 per 100000 live births) and Australian (6.3 per 100000$)$ populations.

The most frequent LSD in the populations of the three countries is Gaucher's disease, its birth prevalence in the Portuguese population (1.4 per 100000 live births) is similar to the one reported in the Netherlands and in Australia, 1.2 and 1.8 per 100000 live births, respectively.

Concerning birth prevalence values higher than 0.5 per 100000 live births in the three populations, the Portuguese present higher prevalence values of GM2 gangliosidoses, mucolipidoses II/III, NPC and MLD, and lower prevalence values of Pompe and Fabry diseases. The highest value for a single LSD is observed with GM2 gangliosidosis, B variant in the Portuguese (3.1 per 100000 live births), which is considerably higher than the highest prevalence of a single LSD in The Netherlands, Pompe disease (2 per 100 000) and Gaucher's disease (1.8 per 100000$)$ in Australia.

As happens with other genetic diseases, LSDs are genetically very heterogeneous. ${ }^{1}$ However, in certain ethnic groups, a high incidence of specific mutations has been described. The high frequency of HEXA mutations associated with the classic infantile form of Tay-Sachs disease observed among the Ashkenazi Jews (1/4100) as compared with the one observed within the non-Jewish individuals $(1 / 112000)^{12}$ is an example. Another example is Gaucher's disease N370S GBA mutation, presenting a frequency of $1 / 17.5$ among the Ashkenazi Jews ${ }^{13}$ contrasting with a $1 / 210$ frequency in a non-Ashkenazi population. ${ }^{14}$
Genotype analysis of the Portuguese patients presenting GM2 gangliosidosis showed that R178 H HEXA mutation (DN allele) represents $58 \%$ of the mutated alleles; $44 \%$ of the patients are homozygous for this mutation, corresponding to a juvenile form of Tay-Sachs B1 variant. ${ }^{15}$ Except for two Spanish patients originated from Galiza ${ }^{16}$ no other patients homozygous for 'DN-allele' were, to our knowledge, described in the literature.

Similarly, in the case of Portuguese patients with MLD, a single ARSA mutation, IVS2 + 1GA (allele I), represents 60\% of the alleles. The higher frequency of this mutation, in comparison with the $15-43 \%$ reported in other European patients, ${ }^{17}$ reflects the higher prevalence of the infantile form detected in the Portuguese patients.

In relation to Gaucher's disease, the N370S GBA mutation represents $53 \%$ of the mutated alleles, a frequency higher than the one reported in non-Ashkenazi GD patients. ${ }^{18}$ According to the gene frequency previously determined in the general Portuguese population ${ }^{14}$ about 200 homozygotes for N370S GBA mutation can be predicted in Portugal, contrasting with 21 homozygotes out of 84 Portuguese Gaucher's disease patients diagnosed. This fact suggests that the great majority of the N370S homozygotes are asymptomatic.

Surprisingly, the higher Niemann-Pick type C prevalence observed in the Portuguese population (2.2 per 100000$)$, as compared with the one estimated in other European (France, West Germany and UK) populations 1/150000, ${ }^{19}$ cannot be explained by a frequent mutation. In fact, a wide genetic heterogeneity was observed, the I1061 T allele of the NPC1 gene, which represents $15 \%$ of the mutant alleles in British and French NPC patients, ${ }^{19}$ represents only $6 \%$ of the NPC1-mutated alleles in the Portuguese NPC patients. ${ }^{20}$

In conclusion, as a group, LSDs can be considered as a very frequent inborn error of metabolism in the Portuguese Population, presenting a birth prevalence (1/4000 live births) higher than birth prevalence reported in the case of PKU (1/12 000 live births) and congenital hypothyroidism (1/6000 live births). ${ }^{21}$

\section{Acknowledgements}

We are grateful to all clinicians who referred cases for LSD study, to Doctors OP van Diggelen, WJ Kleijer (Rotterdam), MT Vanier (Lyon) and DA Wenger (Philadelphia) for invaluable help in difficult diagnoses, and to Mrs Clementina Maia for the search and collection of population data at Instituto Nacional de Estatística, Porto, Portugal.

\section{References}

1 Scriver SR, Beaudet AL, Sly WS, Valle D (eds): The metabolic bases of inherited disease. New-York: McGraw-Hill, 2001, Vol. 3.

2 Poorthuis BJ, Wevers RA, Kleijer WJ et al: The frequency of lysosomal storage diseases in The Netherlands. Hum Genet 1999; 105: 151-156.

3 Meikle PJ, Hopwood JJ, Clague AE, Carey WF: Prevalence of lysosomal storage disorders. JAMA 1999; 281: 249-254. 
4 Wenger D, Williams C: Screening for lysosomal disorders; in Hommes FA (ed): Techniques in diagnostic human biochemical genetics. New York: Wiley-Liss, 1991, pp 587-617.

5 Galjaard H: Genetic metabolic diseases. Early diagnosis and prenatal analysis. Amsterdam: Elsevier/North Holland, 1980.

6 Hopwood JJ, Harrison JR: High resolution electrophoresis of urinary glycosaminoglycans: an improved screening test for the MPS. Anal Biochem 1982; 119: 120-112.

7 Sewell AC: Urinary Oligosaccharides; in Hommes FA (ed): Techniques in diagnostic human biochemical genetics: a laboratory manual. New York: Wiley-Liss, 1991, pp 219-231.

8 Ricketts M, Zhang X, Manowitz P: A method for the rapid detection of arylsulfatase A pseudodeficiency mutations. Hum Hered 1995; 45: 235-240.

9 Wenger D, Rafi M, Luzi P: Molecular genetics of Krabbe Disease (globoid cell leukodystrophy). Diagnostic and clinical implications. Hum Mut 1997; 10: 268-279.

10 Zhong N, Wisniewski KE, Kaczmarski AL et al: Molecular screening of Batten disease: identification of a missense mutation (E295 K) in the CLN3 gene. Hum Genet 1998; 102: 57-62.

11 Amaral O, Marcão A, Pinto E, Ribeiro MG, Sá Miranda MC: Análise do genótipo na prevenção das esfingolipidoses. Arqui Med 1997; 11: 24-26.

12 Gravel RA, Kaback M, Proia R, Sandhoff K, Suzuki K: The GM2gangliosidosis; in Scriver SR, Beaudet AL, Sly WS, Valle D (eds): The metabolic basis of inherited disease. New-York: McGraw-Hill, 2001, pp 3827-3876.

13 Horowitz M, Tzuri G, Eyal N et al: Prevalence of nine mutations among Jewish and non-Jewish Gaucher disease patients. Am J Hum Genet 1993; 53: 921-930.
14 Lacerda L, Amaral O, Pinto R, Oliveira P, Aerts J, Sá Miranda MC: Gaucher Disease: N370S glucocerebrosidase gene frequency in the Portuguese population. Clin Genet 1994; 45: $298-300$.

15 Dos Santos MR, Tanaka A, Sá Miranda MC, Ribeiro MG, Maia M, Suzuki K: GM2-Gangliosidosis B1 variant: analysis of $\beta$-hesosaminidase $\alpha$ gene mutations in 11 patients from a defined region in Portugal. Am J Hum Genet 1991; 49: 886-890.

16 Eiris J, Chabas A, Coll M J, Castro-Gago M: Late infantile and Juvenile form of GM2-gangliosidoses variant B1. Rev Neurol 1999; 29: $435-438$.

17 von Figura K, Gieselman V, Jaeken J: Metachromatic leukodystrophy; in Scriver SR, Beaudet AL, Sly WS, Valle D (eds): The metabolic basis of inherited disease. New-York: McGrawHill, 2001, pp 3695-3724.

18 Koprivica V, Stone DL, Park JK et al: Analysis and classification of 304 mutant alleles in patients with type 1 and type 3 Gaucher disease. Am J Hum Genet 2000; 66: 1777-1786.

19 Patterson M, Vanier MT, Suzuki K et al: Niemann-Pick disease type C: a lipid trafficking disorder; in Scriver SR, Beaudet AL, Sly WS, Valle D (eds): The metabolic basis of inherited disease. New-York: McGraw-Hill, 2001, pp 3611-3633.

20 Ribeiro I, Marcão A, Amaral O, Sá Miranda MC, Vanier MT, Millat G: Niemann-Pick type C disease: NPC1 mutations associated with severe and mild cellular cholesterol trafficking alterations. Hum Genet 2001; 109: 24-32.

21 Osório, R Vilarinho L, Soares J, Almeida M, Carmona C, Martins E: Programa Nacional de Diagnóstico Precoce. Arqui Med 1999; 13: $163-168$ 